\title{
Maqasjid al-shari'ah: suatu kajian terhadap ijtihad Ali ibn Abi Thalib
}

\author{
Eficandra
}

STAIN Batusangkar

ehana2005@yahoocaid

Ijtihadconducted by Ali ibn Abi Talib continuously to understand in depth the purpose of Islamic law and reason for its implementation, and to realize madahah(the public good) for human life on earth. This Ijthadwas always supported by nas(the Q ur'an's and Sunnah's text) and also according to the spirit of Shan'ah The results of Ali's ijthadif linked with the approach and application of maqasidal-shan'ah (the goals and objectives of Islamic law) as the study of usul al-fikih(the methodology of Islamic law) had many similarities. In another sense, Ali ibn Abi Talib was really smart to understand and apply macasidal-shan'ahin the five types of maslahah namely faith or religion, life or human self, intellect, lineage or posterity, and property or wealth. Likewise, in the application of the five maskahth levels and priorities in the form danuiyat(the essential benefits), hijiyyat(the complementary benefits), and tahsiniyyat(the embellishment benefits) was always be considered by him. On the other hand, if there was a clash between one maskahthwith ano ther maskahth Ali ibn Abi Talib solved it by consideration of the level and priority in the implementation of maskahahto be realized.

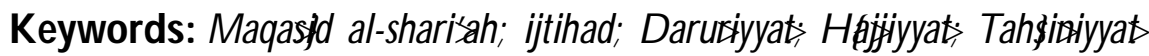

\section{Pendahuluan}

D alam konteks ijtihad hari ini, istilah maqasidal-shar'ah(tujuan pensyariatan hukum dalam Islam) merupakan suatu kajian yang sangat menarik untuk diperbincangkan. Sebab pemahaman tentang maqas)idal-shan'ghmerupakan suatu syarat mutlak yang harus dipenuhi oleh seorang ulama/ mujtahid dalam menyelesaikan problematika hukum yang terjadi di tengah masyarakat.

Sebagai suatu kajian ushul fikih yang baru muncul belakangan, macaidal-shar'łhtampaknya memiliki peranan yang signifikan dan strategis dalam perkembangan dan pembinaan hukum 
dalam Islam, apalagi dalam kehidupan duniawi yang semakin kompleks ini. Problematika hukum yang terjadi di tengah masyarakat semakin menuntut para pakar hukum Islam untuk memberi jawaban dan kepastian hukumnya. Di antara peranan yang dapat dimainkan oleh maqas)d al-shari'gh adalah untuk menjaga pelaksanaan ajaran agama oleh mukallaf dalam kehidupan sehari-harinya, agar dalam pengamalannya secara praktis para ulama/ mujtahid tidak terjebak kepada kemauan hawa nafsu dan kebebasan akal. Di samping itu, maqasidalshar'øh juga bertujuan untuk menjadikan agama Islam berlaku sepanjang zaman dan di mana saja umat Islam itu berada. Bahkan lebih jauh, juga bertujuan untuk mewujudkan kemaslahatan dan kebahagiaan bagi umat Islam dalam kehidupan di dunia dan di akhirat.

\section{Penerapan maqasjid al-shari'ah dalam ijtihad Ali ibn Abi Thalib}

Ijtihad yang dilakukan oleh para sahabat pada periode awal Islam, termasuk Ali ibn Abi Thalib, secara eksplisit tentulah belum kenal dengan istilah maqaidal-shar'æhyang dimunculkan dan dirumuskan oleh ulama ushul fikih belakangan. Namun pemahaman mereka terhadap prinsip-prinsip nasidan kemaslahatan manusia dalam melakukan ijtihad untuk memberikan putusan dan jawaban hukum, agaknya tidak berlebihan bila dikatakan para sahabat tersebut lebih unggul dan lebih memahaminya.

Bahasan dan uraian tentang ijtihad-ijtihad yang dilakukan oleh Ali ibn Abi Thalib dan kejeliannya dalam menetapkan hukum terhadap berbagai kasus hukum yang dihadapinya, bila dilihat dari pendekatan dan penerapan maqasidal-shari'gh (tujuan pensyariatan hukum dalam Islam) dapat diuraikan dan dirinci sebagai berikut:

\section{Kemaslahatan agama}

Berbagai kasus hukum yang muncul, banyak fatwa dan putusan hukum yang dilakukan oleh Ali sebagai hasil ijtihad yang telah dilakukannya dalam rangka memelihara kemaslahatan agama. Ijtihad-ijtihad tersebut bila dihubungkan dengan pendekatan maqasidal-shar'æh maka dapat dikelompokkan menjadi tiga peringkat sesuai dengan tingkat kebutuhan dan kepentingannya, yaitu danniyyat, häjiyyat, dan tahsiriyat.

Pada peringkat danuriyjat, Ali ibn Abi Thalib (Jiy, 1996a: 361 \& al-Thusi, t.th: 128) telah berijtihad sebagaimana ungkapannya; 


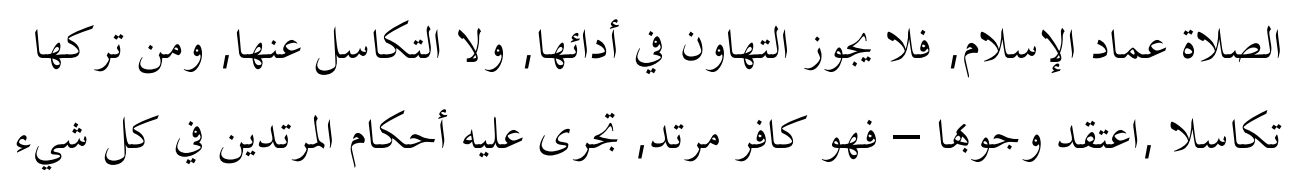

Artinya: ShalatadalahtiangagamaIdam makatidak bodehlalai danmalasdalammdaksamakannya. Siapa yangmeninggalkan shalat denganmalas-bilaiamgakini shalat itu wajib makaiatemasuk kafirmurtad Untuk itu segala sesuaturya belakulahhukuman mutad baginya.

Kutipan di atas menjelaskan bahwa seseorang yang meninggalkan shalat karena malas menurut Ali ibn Abi Thalib dapat dihukum kafir murtad, jika dia meyakini shalat itu wajib. Oleh karena itu segala sesuatunya berlaku hukuman orang murtad (hadnidbah) terhadapnya (Jiy, 1996a: 270). Hukumannya adalah dia disuruh untuk bertaubat sebanyak tiga kali. Jika sudah tiga kali disuruh taubat dia tidak mau, maka dia dibunuh, baik secara perorangan maupun berjamaah. Sedangkan apabila perempuan yang murtad, menurut Ali ibn Abi Thalib hukumannya cukup dengan menawan/ memperbudaknya dan tidak membunuhnya. Sebab menurut Ali ibn Abi Thalib shalat adalah tiang dan pondasinya Islam, sehingga seseorang tidak boleh menganggap remeh kewajiban shalat itu dan bersikap malas untuk melaksanakannya. Sementara sahabat lain (Abu Bakar dan Umar) tidak membedakan antara laki-laki dan perempuan dalam hukuman murtad.

Ijtihad Ali tentang kasus di atas, bila dilihat dari pendekatan maqasidal-shari'ghakan tampak bahwa orang yang tidak mau atau meninggalkan shalat karena malas berarti ia telah mengancam eksistensi agama. Sebagaimana dimaklumi, menjaga eksistensi agama dalam Islam merupakan salah satu aspek yang esensial dan danuiyyat. Untuk itu, orang yang meninggalkan shalat-begitu juga kewajiban-kewajiban lainnya- karena malas berarti ia telah mengabaikan dan melecehkan kewajiban agama. Pengabaian dan pelecehan terhadap kewajiban agama, menurut pandangan Ali, sama halnya keluar dari agama Islam dan sama statusnya dengan orang kafir murtad. Adanya hukuman seperti ini, menurut hemat penulis adalah dalam rangka untuk tetap menjaga eksistensi agama dalam kehidupan seseorang dan tindakan preventif bagi yang lainnya sekaligus juga untuk memelihara tetap utuh dan tegaknya dasar-dasar agama dalam diri seseorang.

D alam peringkat haijiyyat, Ali ibn Abi Thalib berijtihad dalam hal-hal yang berhubungan dengan pelaksanaan ketentuan agama dengan maksud untuk menghindari kesulitan bagi 
manusia. MenurutAli ibn Abi Thalib, seorang musafir wajib melakukan casardalam shalatnya. Ali ibn Abi Thalib mengungkapkan (Jiy, 1996a: 336-337 \& al-Thusi, t.th: 136 \& 140):

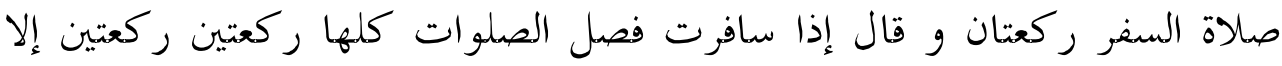

$$
\begin{aligned}
& \text { المغرب فإها ثلاث. و قصر الصالاة في السنر واجب, حتى أنه لو أتم الصلاة لم بجزئه }
\end{aligned}
$$

Artinya: Shalatddlampejalanan adalahduarakaat, lejhlanjutAli ibnAbi Thalibmengungkapkan; A pabila kamu dalampejalanan, maka hendaklah shalat dua rakaat pada semua vaktu shalat keuali shalatmaghib, karena shalat maghibitu dilaksanakan sdbanjak tigarakaat. Mengqasar shalat dalampejalananhukumya adalahwajib Stinggakalausecrangmenjempurnakanrakaat shalatrya sevaktu dalampejalanan, maka tidaklahmmmadai shalatnyaitu.

Berbeda dengan pandangan Usman ibn Affan (Jiy, 1996b: 174) yang hanya memandang hukum boleh saja bagi seseorang untuk meng-gasar shalat dalam perjalanan. Usman tidak memandang wajib hukumnya meng-casar shalat dalam perjalanan sebagaimana pendapat Ali ibn Abi Thalib. Adanya ketentuan qasar dalam shalat menurut pandangan Ali ibn Abi Thalib di atas, menurut hemat penulis sejalan dengan prinsip dan ruh syariat dalam rangka memberi kemudahan dan menghindari kesulitan bagi manusia yang dalam perjalanan. Sesuai dengan Firman Allah swt. dalam al-Q ur'an yang berbunyi:

$$
\text { يريد الله بكم اليسر ولا يريد بكم العسر (البقرة: } 185 \text { ) }
$$

Artinya: Allahmenghendaki kemudahan bag kamu dantidak menghendaki kesusahanbagimu.

D alam ayat lain Allah swt. juga berfirman:

$$
\text { و ما جعل عليكم في اللدين من حرج ( المحج : } 78 \text { ) }
$$

\section{Artinya: Allahtidak mengadakankesempitan bagimu dalamagama.}

Begitu juga di sisi lain, bergeraknya seseorang dari tempat kediamannya menuju suatu tempat yang ditujunya melalui perjalanan, tentulah memberi pengaruh dan efek baginya, baik secara fisik maupun non-fisik. Sehingga langsung atau tidak langsung akan menimbulkan kesulitan bagi seseorang untuk melakukan ketentuan agama -dalam hal ini shalat- secara 'azimahsebagaimana ketentuan yang berlaku bagi orang yang menetap/ muqim O leh karena itu, gasardalam shalat bagi orang yang sedang dalam perjalanan menurut pandangan Ali ibn 
Abi Thalib dapat dipahami bahwa itulah ketentuan Allah bagi orang yang sedang dalam perjalanan.

Sedangkan dalam peringkat tahłiriyjat pada maqasid al-shar'ah dalam rangka menjaga kemaslahatan agama bagi manusia, Ali ibn Abi Thalib (Jiy, 1996a: 384-385 \& al-Thusi, t.th: 152) berijtihad akan keutamaan shalat berjamaah, sebagaimana ungkapannya kepada Abu Darda';

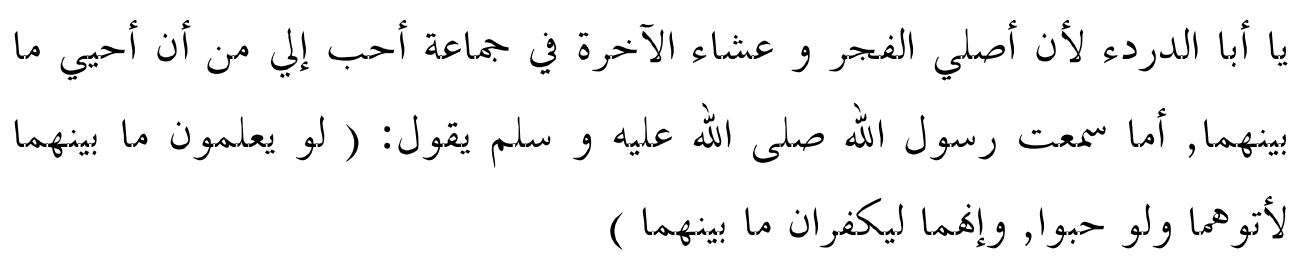

Artinya: YaAbuDarda'; Sesungghnyashalat subuhsampai shalat isja dalamkeadaanbejjamaah lejihakusenang dari padaaku hidupdi antara keduanya. Sebabakumendengar RasulullahSAW bessabda: Kalau manusa tahu apa di antara keduanya (shalat subuh sampai shalat isja), sungguh merka akan mendatanginya untuk bejamaah skalipun dalamkeadaan merandkak, słbab akan dapat menutupi apa saja di antara keduanya.

Namun demikian, menurut analisa penulis, Ali ibn Abi Thalib tidaklah memandang wajib baik secara fard/aynmaupun fard/kifayahpelaksanaan shalat berjamaah. Sebab shalat berjamaah sifatnya adalah penyempuma kewajiban shalat yang dilakukan seseorang dalam rangka memperindah dan mempercantik amalan agama yang dilakukannya itu. Akan tetapi di sisi lain, Ali ibn Abi Thalib mengatakan bagi orang yang berada di samping masjid agar dapat melaksanakan shalatnya di masjid.

\section{Kemaslahatan jiwa}

Dalam berbagai kesempatan yang ada, Ali ibn Abi Thalib telah mengeluarkan fatwa dan putusan hukum sebagai hasil ijtihad yang telah dilakukannya dalam rangka memelihara kemaslahatan jiwa seseorang. Ijtihad-ijtihad tersebut bila dihubungkan dengan pendekatan maqas)dal-shar'łh maka dapat dikelompokkan menjadi tiga peringkat sesuai dengan tingkat kebutuhan dan kepentingannya, yaitu danuriyat, hijijyyat, dan tahkiriyat:

Pada peringkat danuiyyat, Ali ibn Abi Thalib berijtihad bahwa wajibnya had qissas/dalam pembunuhan yang dilakukan secara sengaja, sebagaimana ungkapannya dalam riwayat berikut 
(Jiy, 1996a: 191 \& al-Thusi, t.th: 3):

$$
\begin{aligned}
& \text { و قد تقدمت قصة الرجل الذي قتل ذميا, وقامت عليه البينة, فأمر علي بقتله, فجاء } \\
& \text { أخو البحني عليه فقال: (( إني قد عفوت )), فقال له علي: (( لعلوم هددوك ؟ )) } \\
& \text { قال: (( لا, ولكن قتله لا يرد علي أخي, وعوضو في فرضيت )), فأجاز علي رضي } \\
& \text { الله عنه عفوه . }
\end{aligned}
$$

Artinya: Dalamsuatu peistiva dijdaskan bahwa secrangtdahtedoukti menbunuhkafirzimmi, makaAli ibnAbi Thalibmenyunuhuntuk menbumuhnya. Lalu saudara si korbanmendatang Ali dan bekkata: Sesungghnya aku tdah mmaafkannya. Kemudian Ali ibn Abi Thalib betanya: Mungkinmedkamengancamm? Ia (saudarasi korban) mejjavab. Tidak, akanttaapi membunuh arangitutidak akanmengembalikansaudarakulag, untuk ituakuridhaapabilaiahanyamenbei ganti nug. MakaAli ibnAbi Thalibr.a menbdenkannya untuk memaafkan.

Berdasarkan riwayat di atas, apabila keluarga si korban memaafkan pelaku pembunuhan tersebut, maka hadqisłsmenjadi gugur namun wajib bagi si pembunuh itu untuk membayar diyat kepada keluarga si korban sebanyak 100 ekor unta yang terdiri dari; 33 ekor jadha'ah (unta betina umur 4-5 tahun), 33 ekor hilqqah (unta betina umur 3-4 tahun), dan 34 ekor khilfah(unta betina yang bunting).

Adanya ketentuan qishas/atau pembayaran dyat dalam pembunuhan secara sengaja dan tanpa hak adalah dalam upaya senantiasa menjaga dan memeliharajiwa seseorang yang telah dihilangkan oleh orang lain secara tidak hak, sekaligus juga sebagai tindakan preventif bagi orang lain. Sebab, begitu berat hukuman yang akan diterimanya diharapkan akan dapat mencegahnya untuk tidak melakukan pembunuhan terhadap orang lain.

D alam suatu kasus lain, sewaktu Ali menjadi qad di Yaman, ia pernah dihadapkan tentang suatu perkarayang kemudian dikenal dengan istilah "al-zubyah", yaitu sebuah lubang perangkap binatang buas yang digali di ketinggian lereng-lereng bukit yang tidak terjangkau oleh aliran air. Lubang tersebut digali kemudian ditutupi rerumputan atau sejenisnya untuk menjebak singa hingga terperosok ke dalamnya (Muhammad, 1988: 27). Kasus al-zubjahini berawal dari terperosoknya salah seorang dari sekumpulan orang yang berada di tepi lubang. Tetapi sebelumnya ia sempat menarik seseorang sehingga ikut terperosok pula ke dalamnya. Sebelum 
terperosok bersama orang pertama, orang kedua ini sempat pula menarik orang yang ketiga, bahkan orang ketiga pun juga sempat menarik orang yang keempat, sehingga mereka samasama terperosok ke dalam lubang tersebut yang akhirnya dimangsa oleh singa yang telah terlebih dahulu terperosok ke dalamnya.

Ketika kasus tersebut dihadapkan kepada Ali, maka Ali memutuskan seperempat diyat bagi ahli waris orang pertama, sepertiga diyat bagi ahli waris orang kedua, setengah diyat bagi ahli waris orang ketiga, dan diyat penuh bagi ahli waris orang keempat. Putusan Ali seperti ini disetujui dan disahkan oleh Rasulullah SAW setelah ada di antara mereka yang keberatan atas keputusan Ali tersebut (Muhammad, 1988: 27, Jiy, 1996a: 177 \& Hanbal, 1994: 168).

Adapun yang menjadi dasar pemikiran bagi Ali untuk memutuskan hukum seperti itu adalah qijas (kaidah umum) dan rasa keadilan. Sebab perbuatan jinayah apabila terjadi dikarenakan oleh diri sendiri dan orang lain bersama-sama, maka gugurlah setengah hukuman sebagai akibat dari perbuatannya sendiri dan tetaplah setengah hukuman yang lain sebagai akibat dari perbuatan orang lain atas dirinya. Sehingga mereka yang terperosok ke dalam lubang tersebut mengakibatkan saling terbunuh satu sama lain di antara mereka berempat. A tas dasar itulah pembagian dyatterhadap mereka tidak sama sesuai dengan kesalahan yang mereka lakukan.

Di samping itu, menurut Ali kewajiban diyatitu dibebankan kepada orang yang masih hidup dan tidak terporosok ke dalam lubang. Keputusan hukum ini pun juga didasari oleh rasa keadilan yang diinginkan oleh ajaran Islam. Sebab mereka yang berada di tepi lubang secara beramai-ramai dan berdesakan itu yang mengakibatkan orang yang berempat terperosok ke dalam lubang perangkap singa. Untuk itu, merekalah yang lebih layak dan pantas untuk membayar diyat kepada ahli waris keempat orang yang terbunuh itu dibandingkan ahli waris dari empat orang yang terbunuh itu saling membayar diyatdi antara mereka satu sama lain (Muhammad, 1988: 28 \& al-Jauziyyah, 1977: 39-40).

Ijtihad Ali tentang kasus di atasjika dianalisa dari sisi maqajdal-shar'æhakan memperlihatkan betapa ketajaman pemikiran Ali dalam berfatwa dan mengeluarkan keputusan hukum dalam rangka memelihara betapa pentingnya untuk menjaga dan melindungi jiwa seseorang yang terbunuh tanpa hak. Sekaligus juga untuk menerapkan rasa keadilan dan ruh-ruh syariat 
dalam rangka mewujudkan kemaslahatan bagi manusia.

Sementara dalam peringkat hajiyyat, ijtihad Ali ibn Abi Thalib dalam hal-hal yang berhubungan dengan pemeliharaan terhadap jiwa seseorang adalah dengan maksud untuk menghindari kesulitan hidup bagi manusia. Menurut Ali ibn Abi Thalib tersebut (Jiy, 1996a: 420 \& 260 \& al-Thusi, t.th: 256), seseorang dibolehkan untuk melakukan buruan terhadap binatang dalam rangka memenuhi kebutuhan hidupnya. Persyaratan kebolehan itu sama dengan syarat yang juga berlaku terhadap penyembelihan. Di antara persyaratannya adalah dilakukan oleh seorang muslim dan menyebut nama Allah SWT "bismillah" ketika menyembelih atau melepaskan hewan buruannya. Sehingga sembelihan dan buruan orang Majusi pada dasarnya adalah haram untuk dimakan, karena mereka tidak tergolong kepada Ahlul Kitab yang disebut dalam al-Qur'an (Q S. 2: 173, Q S. 5: 3, 4, dan 5, serta Q S. 6: 145). Akan tetapi Ali memandang makruh hasil buruan (binatang laut maupun darat) yang dilakukan oleh orang Majusi tersebut, baik yang dilakukan dengan pedang maupun dengan binatang buruan.

Adanya ketentuan ini, bila dilihat dari pendekatan maqas)dal-shar'æhakan tampak bahwa Ali ibn Abi Thalib memandang begitu pentingnya memelihara jiwa seseorang dalam rangka memenuhi kebutuhan hidupnya. Lebih lanjut kemakruhan hasil buruan orang Majusi, menurut hemat penulis disebabkan bahwa buruan tidaklah persis sama dengan sembelihan yang dilakukan tanpa menyebut nama Allah swt.

Sedangkan dalam peringkat tahłiriysat pada maqasid al-shari'ah dalam rangka menjaga kemaslahatan jiwa bagi manusia, seseorang diatur dan ditetapkan tentang tata cara makan dan minum bagi mereka. Adanya ketentuan ini hanyalah bersifat penyempurna bagi seseorang dalam hal yang berhubungan dengan sopan santun dan tata krama. Sehingga sama sekali tidak mengancam eksistensi kehidupan manusia atau akan mempersulitkehidupannya. D alam keadaan tertentu, Ali ibn Abi Thalib (Jiy, 1996a: 100) memandang boleh bagi seseorang minum dalam keadaan berdiri. Sebagaimana riwayat berikut ini:

$$
\begin{aligned}
& \text { كان علي كرم الله وجهه لا يرى بأسا بالشرب قائما, فقد أتي بكوز ماء فأخذ منه } \\
& \text { حفنة واحدة فمسح بها وجهه و يديه ورأسه ورجليه, ثم قام فشرب فضله وهو قائم } \\
& \text { ثم قال: (( إنا ناسا يكرهون الشرب قائما وإن رسول الله شرب قائما )). }
\end{aligned}
$$


Artinya: Ali ibnAbi Thalibk.wmemandangtidak aptapa(bddh) minumdalamkeadaanberdin. Karena ia pemah disuguhi seangkir air, lalu diambilnya dengan satu tdapak tangan, kemudan diusapkannya kepada wajah tangan, rambut, dankakinya Lalubedin danmeminumsisa airitu dalamkeadaan bedini tessat dan bekkata: Sesungghnya manusiamembeni minumdalamkeadaan berdin, padahal RasulullahSAW pernah minumdalamkeadaan bedin.

D emikianlah pandangan dan cara yang dilakukan Ali dalam hal seseorang minum dalam keadaan berdiri. Menurut hemat penulis, kebolehan ini agaknya sesuai dengan situasi dan kondisi yang melatarbelakanginya serta kultur yang berlaku bagi masyarakat setempat. Karena hal ini hanyalah bersifat etika dan kesopanan saja bagi seseorang dalam memenuhi kebutuhan hidupnya.

\section{Kemaslahatan akal}

Untuk menjaga dan memelihara kemaslahatan akal bagi seseorang, pada berbagai kesempatan dalam sisi-sisi kehidupannya, Ali ibn Abi Thalib mengeluarkan fatwa dan putusan hukum sebagai hasil ijtihad yang telah dilakukannya dalam rangka memelihara kemaslahatan akal seseorang tersebut. Ijtihad-ijtihad itu bila dihubungkan dengan pendekatan maqasidal-shar'æh maka dapat dikelompokkan kepada danniyyatdan hïjijyatsesuai dengan tingkat kebutuhan dan kepentingannya.

Ali ibn Abi Thalib (Jiy, 1996a: 97-98, al-Thusi, t.th: 60, Muhammad, 1988:101 \& alMahmashani, 1984: 21), pada peringkat danuiyattelah berijtihad bahwa wajibnya had meminum minuman khamr sebanyak 80 kali dera bagi pelakunya, baik sedikit maupun banyak. Sementara pada zaman Nabi SAW, Abu Bakar, dan sebagian zaman Umar had meminum khamrhanyalah 40 kali dera.

A danya ketentuan ini menurut Ali adalah untuk menjaga dan memelihara akal seseorang agar tidak terancam eksistensi akalnya. Sebab akal-lah yang membedakan manusia dengan makhluk lainnya sekaligus akal juga yang menjadikan manusia sebagai khalifah di atas bumi. Oleh karena itu, tidak berfungsi dan hilangnya akal seseorang akan bisa mengakibatkan timpangnya kehidupan manusia serta dapat menimbulkan kerusakan di atas bumi.

Ketentuan 80 kali dera tersebut ditetapkan oleh Ali berdasarkan qiyas kepada hadqadhaf (menuduh berzina) dan didasari juga kepada saddal-dhan'ah Sebab menurut Ali, sebagaimana riwayat yang diungkapkan oleh Imam Malik (Malik, 1989: 562); 


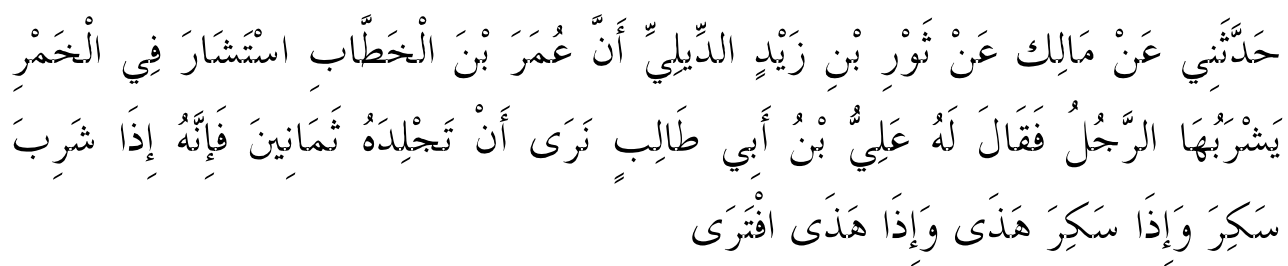

Artinya: Diniwayatkandari Malik, ThauribnZaidal-DailiyybahmaUnmaribnKhattabmeminta pendapat sahabat tentang ketentuan hukuman bag peninum khamr. Ali berpendapat bahma hukumannya adalah80 kali dara. Karena apabila seorangmeminumkhammmaiaakanmabuk, apabila ia mabuk akalnya akan hilang dan apabila akalnya hilangia akanmmiggau.

Menurut Ali ibn Abi Thalib atas dasar qiyas, orang yang mengigau pembicaraannya tidak akan terkontrol, untuk itu hukumannya sama dengan had qadhaf (orang yang menuduh berzina) yakni 80 kali dera. Begitu juga atas dasar saddal-dhan'ah agar peminum khamrtidak terjebak kepada perbuatan qadhaf, maka perlu dicegah perbuatan tersebut dengan memberi sanksi baginya. Berdasarkan qiyas dan sadd al-dhar'gh inilah, ditetapkan bahwa hukuman bagi peminum khamr adalah sebanyak 80 kali dera. Ketentuan seperti ini berlaku sampai akhir hayatnya. Sehingga Ali mengatakan; hukuman bagi peminum khamr adalah 80 kali dera, baik sedikit maupun banyak.

Di samping itu, untuk lebih menjaga eksistensi akal manusia ini, Ali juga berijtihad (Jiy, 1996a: 95-98) bahwa cakupan makna khamrsangatlah luas, sehingga ia mengatakan bahwa khamr adalah suatu nama yang meliputi segala sesuatu yang mengakibatkan mabuk dan tertutupnya akal, baik berasal dari anggur, korma, madu lebah, maupun yang lainnya. Untuk itu dalam suatu riwayat, Ali pernah mengatakan hukuman bagi peminum mabidh (kurma yang diproses menjadi minuman keras) adalah 80 kali dera.

Dalam kesempatan lain, Ali juga pernah berijtihad dengan memerintahkan untuk membakar suatu tempat atau perkampungan yang terkenal dengan perdagangan khamr di dalamnya. Karena dengan tindakan tersebut diharapkan dapat mencegah tersebar luasnya khamryang dijadikan sebagai barang komoditi di tempat itu (Jiy, 1996a: 95-98). Berdasarkan sebuah riwayat, sebagaimana yang diungkapkan oleh Abu Ubaid (Jiy, 1996c: 95-98 \& Salam, 1986: 105) dalam kitabnya al-Ammał bahwasanya Ali memandang ke arah suatu perkampungan yang bernama Zararah, kemudian ia bertanya: “Kampung apa ini?” , mereka 
yang berada di sekitarnya menjawab: "Ini sebuah perkampungan yang bernama Zararah, di situ khamr dikumpulkan dan diperjualbelikan". Kemudian Ali bertanya lagi: "Mana jalan untuk menuju ke sana?", mereka menjawab: "Babul Jisri (Pintu Jembatan)", kemudian seseorang berkata: "Wahai Amirul Mukminin, akan kami sediakan kapal air yang dapat membawamu ke tempat itu", Ali menjawab: "Itu sama saja dengan menghina (manusia), kita tidak perlu menghina (sesama), mari kita berangkat ke Babul Jisri (Pintu Jembatan). Maka berjalanlah Ali hingga sampai ke tempat yang dituju, lalu berkata: "Cari api dan bakarlah tempatitu, karena sesungguhnya kejahatan saling memakan satu sama lain". Menurut riwayat lain bahwa perkampungan itu terbakar dari kedua sisi Baratnya hingga mencapai kebun Khuwastabi Jabrauna.

Tindakan ini dilakukan oleh Ali, tentu dengan maksud untuk lebih menjaga eksistensi akal manusia secara universal. Supaya perbuatan yang dilakukan oleh sekelompok orang tidak akan merugikan kepada orang yang lebih banyak, meskipun menimbulkan kemudharatan bagi penduduk perkampungan Zararah itu. Tindakan preventif Ali seperti ini sejalan dengan prinsip dan ruh syariat yang terdapat dalam al-Q ur'an dan Sunnah yang lebih lanjut dijabarkan oleh ulama ushul dalam kaidah fikihiyah yang berbunyi:

الضرر يزال (al-Zarqa, 1996: 179 \& al-Nadwi, 1986: 252)

Artinya: Kemudharatan itu harus dihilangkan/ dilenyapkan.

الضرر يدفع بقدر الادكان (al-Zarqa, 1996: 207)

Artinya: Kemudharatan itu harus dicegah sedapat mungkin.

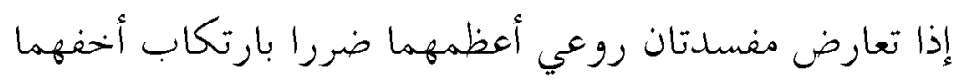

(al-Zarqa, 1996: 201 \& al-Nadwi, 1986: 276)

Artinya: A pabila betemuduamafsadah(kemudharatan), makayanglebihbesarkemudharatannya hanus dutamakan denganmengorbankanyanglebihningan kemudharatamnja.

يتحمل الضرر الخاص لد فع الضرر العام (al-Zarqa, 1996: 197 \& al-Nadwi, 1986: 385)

Artinya: Ditanggulkan kemudharatan yang bessifat khusus untuk mendak kemudharatan yang besifatumm 
Atas dasar kaidah-kaidah fikihiyah di atas menyelamatkan kemaslahatan yang lebih besar dalam rangka memelihara dan menjaga eksistensi akal manusia secara universal lebih utama dari pada menyelamatkan perkampungan Zararah itu. Karena tersebar luasnya khamr dari tempat itu yang dijadikan sebagai barang komoditi untuk diperjualbelikan, merupakan kemudharatan yang lebih besar dari pada kemudharatan yang akan ditimbulkan oleh akibat pembakaran itu.

Dalam peringkat hoijiyyat, ijtihad Ali ibn Abi Thalib dalam hal-hal yang berhubungan dengan pemeliharaan terhadap eksistensi akal manusia adalah dengan maksud untuk menghindari kesulitan hidup bagi diri seseorang dalam kaitannya dengan pengembangan ilmu pengetahuan. Menurut Ali ibn Abi Thalib sebagaimana wasiatnya kepada Kumail ibn Ziyad (Jiy, 1996a: 468-469) dengan ungkapan:

$$
\begin{aligned}
& \text { قال علي بن أبي طالب : يا كميل بن زياد , القلوب أوعية فخيرها أوعاها , احفظ } \\
& \text { ما أقول لك , الناس ثلاثية : فعالم و باني , و متعلم على سبيل نجاة , وهمج رعاع } \\
& \text { أتباع كل ناعق يميلون مع كل ريح , و لم يستضيئوا بنور العلم , و لم يلجأوا إلى } \\
& \text { ركن وثيق. العلم خير من المال , العلم يثر سك وأنت تخرس المال , العنم يزكو على } \\
& \text { العمل , والمال تنقصه النفقة , ومحبة العالم دين يدان به , العلم يكسب العالم الطاعة } \\
& \text { في حياته و جميل الأحدوثة بعد موته , وصنيعة المال تزول بزواله , مات خزان } \\
& \text { الأموال وهم أحياء , والعلماء باقون ما بقي الدهر , أعياهـم مفقودة وأمثالهم في }
\end{aligned}
$$

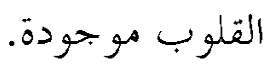

Artinya: Ali ibnAlbi Thalibbekkata: Hai Kumail ibnZiyad, sesungghinya hati ituibaratkantong kantong scbaik-baik hati adalahhati yangsenantiasasadar dansiapmeneima pengisian. Untuk itu, ingatlah pekkataanku ini. Manusia terbag kepada tiga gdangan: abli ilmu yangreligus penuntut ilmu yangmencari kdbahagiaan, dan crangbodhh yangmudah mengkuti sapa saja (medka tidak meneang jalan medka denganilmu dan tidak berpegang teguh kepada pegancan yangkuat). Ilmu leihbaik dari padaharta. Denganilmukamuakan terpdihara, sedangkanhartakamujangakan memdiharanya. Ilmuakanmendapatmeryuikanamalan, sedangkanhartaakan bekkurangdangan perbdanjaan Begitujuga menintai ahli ilmuadalahsuatukenmatan Denganilmuserangakan 
mempeddhkktaatan dalamhidupnja dan urapan-urapan baik stdahiammingygl, sedangkan peibuatan menari hartaakanlenyapdanganlenyapnyaharta Bag pengumpul harta hatinyaakannati, selangkan jasadnya mash ttaphidup Nammulama (ahli ilmu) senantiasa hidupsepanjangmasa. Skkalipun jasadulama (alli ilmu) tessauttdahtiada, namnajaran-ajaranmedkattaphidupdi hati manusia.

Demikianlah anjuran Ali ibn Abi Thalib agar manusia senantiasa mempelajari dan mendalami ilmu pengetahuan. Sebab dengan ilmu seseorang akan terpelihara dalam hidup di dunia ini. D engan ilmu juga orang akan dapat menyempurnakan dan menyucikan amalanamalan yang diperintahkan oleh Allah SWT kepadanya. Namun demikian pengabaian terhadap hal ini tidaklah merusak akal manusia secara langsung, akan tetapi hanyalah akan mempersulit diri seseorang tersebut dalam kehidupan dunia ini.

\section{Kemaslahatan keturunan/ nasab}

Untuk mewujudkan kemaslahatan keturunan/ nasab bagi seseorang, pada berbagai kesempatan yang ada, Ali ibn Abi Thalib telah berfatwa dan mengeluarkan putusan hukum sebagai hasil ijtihad yang telah dilakukannya demi menjaga dan memelihara kemaslahatan keturunan/ nasab seseorang tersebut. Ijtihad-ijtihad itu bila dihubungkan dengan pendekatan maqajidal-shar'łh maka dapat dikelompokkan menjadi tiga peringkat sesuai dengan tingkat kebutuhan dan kepentingannya, yaitu danuiyjat, hijijiyat, dan tahłiriysat.

Pada peringkat danuriyat, Ali ibn Abi Thalib (Jiy, 1996a: 580-586) memandang bahwa nikah sangat dianjurkan dan disyariatkan dalam Islam. Sebab nikah merupakan sarana dan wadah yang sah untuk tetap melanjutkan keturunan umat manusia di atas bumi. Oleh karena itu, perbuatan zina sangat dilarang dalam Islam dengan larangan yang sangat tegas dan keras. Terjadinya perzinaan akan dapat mengacaukan dan mengancam eksistensi keturunan, begitu juga perbuatan shaq (homoseks sesama wanita/ lesbian) dan livat (homoseks sesama pria/ sodomi). Untuk itu adanya pernikahan diharapkan lahimya anak yang memiliki nasab kepada seseorang tertentu. Keberadaan nasab seseorang kepada orang tertentu, dalam pandangan hukum Islam membawa konsekuensi dan dampak hukum yang banyak dalam kehidupan beragama. D alam hal penentuan nasab seseorang, Ali sangat berhati-hati dalam mengeluarkan ijtihadnya. Hal ini terlihat dari pemikiran fikihnya dalam menentukan minimal masa kehamilan seorang perempuan. Kajian ini pada akhirnya dalam kajian fikih dikenal dengan istilah "acal muddahal-hłan”'. Imam Malik (Malik, 1989: 548) dalam kitabnya mengemukakan; 


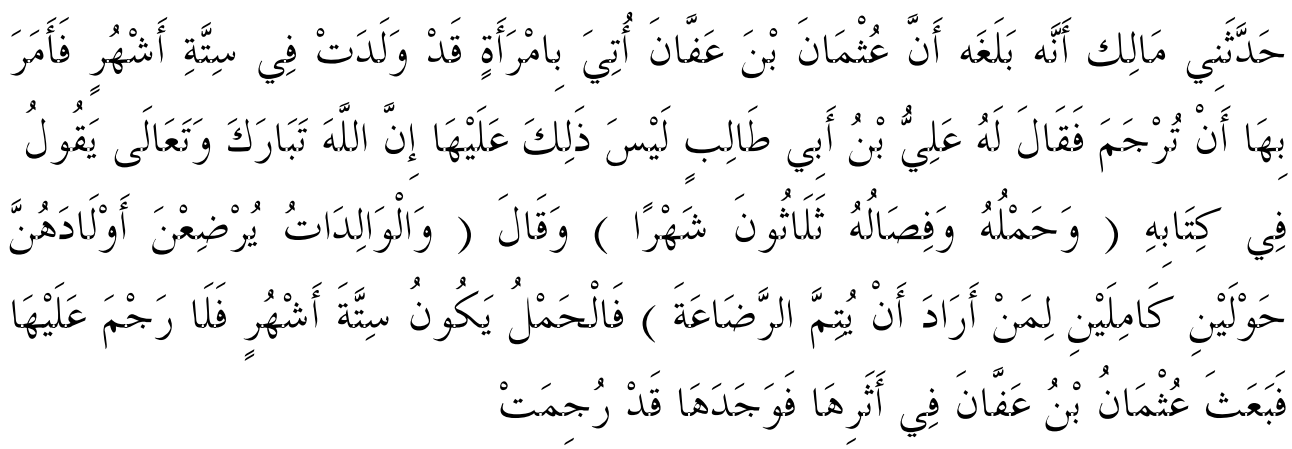

Artinya: Diniwayatkan dari Malik bahwa Usman ibn Affan menghadapi kasus wanita yang mdahirkankandungannyastdahenambulan Usmanmemeintahkan untuk meajamwanitatesdat. Namm Ali ibn Abi Thalib bekkata kepadanya: Tidak ada hukuman rajambag wanita itu. KarenaAllahsut. befimmandalamal-Qur'an (ibunyatdahmengandungsampai menyaphnyaadalah tiga puluh bulan) dan fiman Allah sut. dalamsurat yanglain (para ibu hendaklah meryusukan anaknya sdama dua tahun penuh, yaitu bag yenginginmenyempumakan penyusuan). Olehkarena itu, masa kehamilantessdat adalahenambulan, shingga tidak ada hukuman rajambag vanitaitu KemudianUsman perg் ketempat vanitaitu, namniamendapeti wanita itutdahdijatuhi hukuman rajam

Adapun menurut riwayat lain (al-Thaba'i, 1991: 205, al-Zuhaili, 1991: 33-34 dan 364, Jiy, 1996a: 253 dan 316 \& Muhammad, 1988: 43) dijelaskan juga bahwa pemikiran Ali tentang kasus ini, berawal dari sebuah kisah seorang wanita yang melahirkan anaknya setelah enam bulan usia perkawinannya. Melihat kondisi ini, maka suaminya terkejut dan tercengang, sehingga ia menyangka bahwa isterinya itu berkemungkinan telah berzina sebelumnya. Lalu diajukanlah masalah ini kepada khalifah Usman (menurut riwayat lain khalifah Umar). Setelah itu khalifah menemui wanita tersebut dan memintanya untuk menghadap di hadapannya. Ketika wanita itu akan menghadap, ia sempat menangis dan berucap kepada saudara perempuannya. D emi Allah, tidak ada seorang laki-laki pun yang menggauliku kecuali suamiku. Biarlah Allah memutuskan apa yang dikehendaki-Nya atas diriku. Sesampai di hadapan khalifah, ia menceritakan dengan sebenarnya kondisi kehamilan yang enam bulan itu. Maka khalifah Usman memerintahkan untuk merajamnya sebagai hukuman bagi orang yang berzina.

Putusan yang diberikan Usman tersebut, sempat sampai didengar oleh Ali, dan Ali segera untuk menemui khalifah dan bertanya: “Apa yang engkau perbuat atas wanita itu?”. Usman menjawab: "Dia melahirkan anaknya setelah enam bulan masa perkawinannya, apakah 
mungkin hal itu terjadi?”. Kemudian Ali bertanya kembali: "Apakah engkau tidak pernah membaca al-Q ur'an?”. Usman menjawab: “Tentu... ... aku selalu membacanya”. Kemudian Ali bertanya kembali: "A pakah engkau tidak pernah mendengar firman Allah yang berbunyi;

وحمله وفصاله ثلاثون شهرا ( الأحقاف : 15 )

Artinya: Mengandungnya sampai menyapihnya adalahtigapuluhbulan

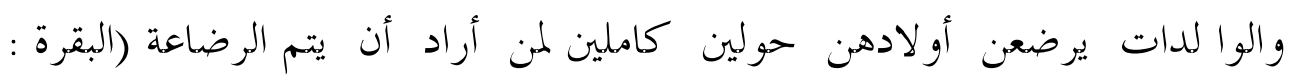

Artinya: Para ibu hendaklahmeryusukan anaknja sdama dua tahun penuh jaitu bag yangingin meiyempurnakan peryusuan.

A tas dasar dua ayat itu, Ali bertanya: "Bukankah akan engkau dapati masa yang tersisa yaitu enam bulan untuk masa kehamilan?" Usman menyadari kekeliruannya seraya berkata: "D emi Allah, aku tidak berpikir sejauh itu. Kalau begitu aku harus membebaskan wanita tersebut". Sehingga hukuman rajam yang akan diterapkan kepadanya tidak jadi untuk dilaksanakan. Namun amat disayangkan, Usman mendapati wanitaitu telah terlanjur dijatuhi hukuman rajam.

Berdasarkan kasus di atas, terlihat begitu cemerlangnya pandangan dan pemahaman Ali tentang masa minimal kehamilan seorang perempuan dengan cara menggabungkan dua kandungan ayatal-Q ur'an. Lebih lanjut, pendapat dan ijtihadnya ini bila dilihat dari pendekatan maqas)dal-shar'yh memperlihatkan begitu pentingnya untuk menentukan nasab seseorang. Sebab ketidakjelasan nasab seseorang akan dapat mengancam eksistensi keturunan umat manusia. Sebagaimana dimaklumi, menjaga dan memelihara eksistensi keturunan dalam Islam merupakan salah satu aspek yang esensial dan danuixyat Untuk itu, menurut pandangan Ali, kecerobohan dan ketidakhati-hatian dalam menentukan minimal masa kehamilan seseorang dapat berakibat fatal dalam penentuan nasab seseorang dan eksistensi hidup mereka di dunia.

D alam peringkat hoijiyyat, Ali ibn Abi Thalib berijtihad dalam hal-hal yang berhubungan dengan pemeliharaan keturunan dengan maksud untuk menghindari kesulitan dan menolak kemudharatan bagi manusia. MenurutAli, demi tercapainya tujuan pernikahan yang mavaddah 
dan rahmah jika dalam perjalanan rumah tangga tersebut seringkali terjadi ketidakharmonisan hubungan suami isteri, maka seorang suami diberi hak thalak sebagai jalan keluar untuk menjaga hubungan sesama manusia. Kendati perbuatan thalak tersebut dalam pandangan Ali ibn Abi Thalib (Jiy, 1996a: 430) merupakan suatu perbuatan buruk yang amat dibenci. Sebagaimana ungkapannya dalam riwayat berikut ini:

$$
\text { قال: إن الطلاق قبيح أكرهه }
$$

Artinya: Ali ibn Abi Thalib berkata: Sesungghinya thalak adalah pedaratan yangbunkk yang sangatakubeni.

Kebenciannya terhadap perbuatan thalak tersebut, terlihat juga dalam perkataannya sendiri ketika Ali menasehati manusia agar tidak mau dikawini oleh Hasan (putranya) dengan ucapan:

$$
\text { فقال: يا أهل العرق ويا أهل الكوفة, لا تزوجوا حسنا فإنه رجل مطلاق. }
$$

Artinya: Ali ibnAli Thalibbekkata: Hai penduduk Irak dan Kufah, jangan mau dikawimi deh Hasan karena ia seranglaki-laki yangsuka menceaikan isteinya.

Sedangkan dalam peringkat tahłiriyjate pada maqasid al-shar'æh dalam rangka menjaga kemaslahatan keturunan/ nasab, Ali ibn Abi Thalib membolehkan seseorang untuk melihat wanita yang dipinangnya dalam rangka mengetahui kecantikan dan segala sesuatu yang membuatnya tertarik dengan wanita itu (Jiy, 1996a: 579). Hal ini terlihat dari ungkapannya kepada Umar, ketika Umar hendak meminang (khitbah) anak perempuannya Umi Kalsum;

$$
\text { فقال علي: (( إها صغيرة فانظر إليها ()) }
$$

Artinya: LaluAli ibnAbi Thalibbekkata: Sesungghnyaia(Umi Kalsum) mashkeil, untuk itu lihatlahia teldihdahulu.

Adanya ketentuan khitbahini menurut hemat penulis bila dihubungkan dengan pendekatan maqas)dal-shar'ahhanyalah bersifat pelengkap dan penyempuma bagi seseorang dalam rangka memelihara dan menjaga eksistensi keturunan mereka melalui pencapaian tujuan pernikahan secara optimal. Pengabaian terhadap ketentuan ini sama sekali tidak mengancam eksistensi keturunan dan tidak pula mempersulit orang yang melakukan pernikahan. 


\section{Kemaslahatan harta}

D alam berbagai kesempatan yang ada, Ali ibn Abi Thalib banyak mengeluarkan fatwa dan putusan hukum sebagai hasil ijtihad yang telah dilakukannya dalam rangka memelihara kemaslahatan harta seseorang. Ijtihad-ijtihad tersebut bila dihubungkan dengan pendekatan maqas)dal-shar'æh maka dapat dikelompokkan menjadi tiga peringkat sesuai dengan tingkat

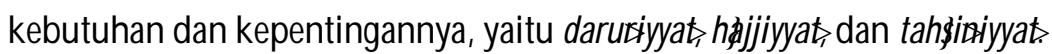

Pada peringkat danuriyat, Ali ibn Abi Thalib (Jiy, 1996a: 328-331) memandang bahwa seseorang tidak dikenai hadpencurian apabila dalam keadaan terpaksa melakukan pencurian demi sekedar untuk memenuhi kebutuhan hidupnya. Ali mengatakan:

$$
\text { قال علي كرم الله وجهه: (( لا قطع في عام سنة)) }
$$

Artinya: Ali ibnAbi Thalibk.wbekkata: "Tidak dibedakukan hukuman potangan tangan pada tahunsannah (masa pancklik/ kekeingan).

Begitu juga dalam pandangan Ali ibn Abi Thalib (Jiy, 1996a: 331 \& al-Mahmashani, 1984: 229), apabila seseorang telah berulang kali melakukan pencurian setelah dipotong sebelah tangan dan sebelah kakinya, kali ketiganya orang tersebut hanya dipenjarakan saja. Berbeda dengan sahabat lain (A bu Bakar, Umar ibn K hattab, Usman ibn Affan, dan Umar ibn Abdul Aziz), mereka menerapkan hukuman potong tangan kiri terhadap pencurian ketiga, potong kaki kanan pada pencurian keempat kalinya. Sedangkan pada pencurian kali kelimanya, Abu Bakar dan Umar men-tázirdan memenjarakannya, sedangkan Usman dan Umar ibn Abdul Aziz membunuh mereka. Terhadap kasus ini, Ali mengatakan sebagaimana riwayat berikut:

$$
\text { فقال: (( إني أستحي من الله أن أقطع يده فبأي شيء يأكلر, أو أقطع رجله فعلى أي }
$$

Artinya: LaluAli ibnAbi Thalibberkata: "Sesungguhnya akumalu padaAllahuntuk monotong tangannya lagं, karena dengan apa ia akan makan. A tau pun memtongkakinja yangsatu lag,, karena dangan apa ia akan bedin.

Berdasarkan ungkapannya itu, Ali ibn Abi Thalib hanya menerapkan hukuman pukulan dan memenjarakannya saja. Bahkan menurut suatu riwayat, ijtihad Ali dalam kasus seperti 
ini, disepakati dan dipegangi oleh sahabat lainnya seperti Umar ibn Khattab, kendati sebelumnya ia berbeda pendapat dengan Ali. Hal ini berawal dari keinginan Umar untuk menerapkan hukuman potongan tangan juga bagi pencurian yang ketiga kalinya. Sebelum dilaksanakan, Ali melarang Umar dengan ungkapannya sebagaimana riwayat berikut:

$$
\text { فقال له علي بن أبي طالب: لا تفعل, إنما عليه يد ورجل }
$$

Artinya: LaluAli ibnAbi Thalibbekkata: Janganlakukan, karenaiahanyamemiliki satutangan dansatukaki saja lag.

Kemudian Ali membacakan ayat al-Q ur'an yang berbunyi:

$$
\begin{aligned}
& \text { إنما جزاء الذين يحاربون الله ورسوله ويسعون في الأرض فسادا أن يقتلوأو أو يصلبوا } \\
& \text { أو تقطع أيديهم وأرجلهم من حلاف أو ينفوا من الأرض (المائدة : 33) }
\end{aligned}
$$

Artinya: Sesungguhnya perbalasan tehadap orangorangyangmemerang Allah dan Rasul-Nya danmerbuat keussakandi mikabum, hanyalahmerekadibunuh, disalib, diptongtangandankaki medka dangan betimbal balik, atau dibuangdari negai (tempat kediamannya).

A tas dasar ayat itu, maka tidaklah pantas memotong kakinya, karena membuat ia tidak bisa berjalan lagi, begitu juga tangannya, karena membuat ia tidak bisa makan lagi dengan tangan itu. Untuk itu hukuman yang akan diterapkan baginya adalah hukuman ta'zir atau dipenjarakan. Maka dalam hal ini, Ali hanya memilih untuk memenjarakannya saja (Jiy, 1996a: 332). Bahkan menurut riwayat lain, Ali memenjarakan orang tersebut sampai meninggal dunia (al-Mahmashani, 1984: 229).

Lebih lanjut ijtihad Ali dalam dua kasus ini, bila dilihat dari pendekatan magasidal-shar'yh terkesan adanya perbenturan antara satu kemaslahatan dengan kemaslahatan lain. Pencurian yang dilakukan karena terpaksa demi menjaga dan mempertahankan hidup/ nyawa seseorang lebih utama dibandingkan dengan memelihara harta orang lain. Begitu juga pemeliharaan terhadap tangan dan kaki seseorang untuk mencari nafkah dan kehidupan mereka dalam rangka memenuhi kemaslahatan jiwa mereka, lebih diutamakan dari pada menerapkan hukuman potong lagi baginya dalam rangka memelihara kemaslahatan harta orang lain. Sebab pemeliharaan terhadap kemaslahatan jiwa berada pada skala prioritas dan urutan yang lebih utama dari pada kemaslahatan harta. 
Sikap yang yang dilakukan oleh Ali itu, agaknya sejalan dengan prinsip dan ruh syariat yang terdapat dalam al-Q ur'an dan Sunnah yang lebih lanjut dijabarkan oleh ulama ushul dalam kaidah fikihiyah yang berbunyi:

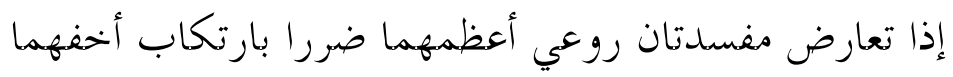

(al-Zarqa, 1996: 201 \& al-Nadwi, 1986: 276)

Artinya: A pabila betemuduamafsadah(kemudharatan), makayanglebihbesarkemudharatannya hanus dutamakan denganmengobankanyangleihningan kemudharatamma.

الضرر الأ شد يزال بالضرر الأ خف (al-Zarqa, 1996: 199 \& al-Nadwi, 1986: 276)

Artinya: Kemudharatan yanglebih kuat hanus dihilangkan dengan mengadbankan kemudharatan yanglebihkeil.

$$
\text { (al-Zarqa, 1996: 168) }
$$

Artinya: A pabilabekkumpul duakemudharatan padasuatuwaktu, makadigugurkankemudharatan yangleihkeil demi mempetahankan kemudharatan yanglebihbesar.

D alam peringkat hijijyat, Ali ibn Abi Thalib berijtihad dalam hal-hal yang berhubungan dengan pemeliharaan harta seseorang dengan maksud untuk menghindari kesulitan bagi mereka. D alam hal ini, seseorang dibolehkan untuk melakukan berbagai macam pola dan bentuk jual beli yang sesuai dengan perkembangan zaman dan kebutuhan manusia. Selama tidak bertentangan dengan ruh dan jiwa syariah serta prinsip-prinsip akad dalam ekonomi Islam. Untuk itu, Ali ibn Abi Thalib membolehkan jual beli dengan cara salamdengan syarat adanya kepastian waktu penyerahan barang yang dibeli itu. Begitu juga, adanya hak khiyar bagi seseorang dalam melakukan transaksi sesama mereka, sebagaimana ungkapannya (Jiy, 1996a: 247):

$$
\text { قال علي: (( المسلمون عند شروطهم )) }
$$

Artinya: Ali ibn Abi Thalib bekkata: Kaummusiminitu sesuai dengan pessyaratan yangmeaka ttapkan

Berdasarkan ungkapan Ali ibn Abi Thalib di atas dipahami bahwa persyaratan yang ditetapkan sesama kaum muslimin dalam jual beli dapat berwujud dalam bentuk adanya hak khiyar padanya. Untuk itu adanya ketentuan ini dalam jual beli diharapkan manusia 
secara mudah dapat melakukan transaksi sesama mereka, serta terhindar dari kesulitan dan kesempitan dalam bertransaksi tersebut.

Sedangkan dalam peringkat tah kemaslahatan harta bagi manusia, seseorang diatur dan ditetapkan tentang tata cara pemilikan harta yang sesuai dengan etika muamalah dalam Islam. Pengabaian terhadap etika ini sama sekali tidaklah mengancam eksistensi harta manusia atau akan mempersulit kehidupan mereka. Untuk itu menurut Ali ibn Abi Thalib (Jiy, 1996a: 474 \& al-Thusi, t.th: 155), seseorang tidak dibolehkan melakukan jual beli yang diwarnai oleh unsur gharar(penipuan), sebagaimana riwayat berikut ini:

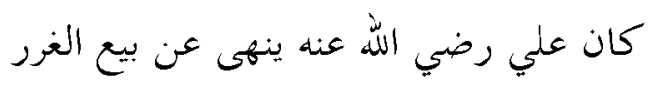

\section{Artinya: Ali ibnAbi Thalibmdarangjual bedi yangmengandungpenipuan}

Kendati ketentuan dan aturan ini hanya berkaitan dengan etika, akan tetapi ketentuan tersebut turut berpengaruh dan berkaitan dengan kesahan jual beli pada peringkat sebelumnya.

\section{Penutup}

D emikian bahasan dan uraian tentang ijtihad yang dilakukan oleh Ali ibn Abi Thalib dalam memutuskan dan menetapkan hukum terhadap berbagai persoalan yang ada jika dilihat dan dihubungkan dengan pendekatan dan penerapan magasidal-shar'ah(tujuan pensyariatan hukum dalam Islam). D iharapkan ketajaman dan kejelian A li dalam berijtihad tersebut dapat dijadikan sebagai dasar dan landasan bagi ulama/ mujtahid hari ini dalam menyelesaikan problematika hukum yang mucul di tengah masyarakat melalui pemahaman yang mendalam tentang pendekatan dan penerapan macasidal-shari'gh(tujuan pensyariatan hukum dalam Islam).

\section{Daftar pustaka}

Hanbal, Imam Ahmad ibn. MusnadAhmadibn Hanbal. Beirut: D as al-Fikr, 1994. Al-Jauziyyah, Ibn Q ayyim. I'lamal-Mumaci'inanRabbal-Alamin Beirut: D asal-Jail, 1977. Jiy, Muhammad Ruwas Q al'ah. Mausúah FikihImamAli. D amaskus: Das al-Fikr, 1996a. Jiy, Muhammad Ruwas Q al'ah. MausúahFikihUthmanibnAffan D amaskus: D aæal-Nafałs, 1996b. 
Jiy, Muhammad Ruwas Qal'ah. Mausuah Fiqh Zaid ibn Thalit. Damaskus: Dar al-Nafałis, 1996c.

Malik, Imam. al-Munattjá li al-ImamMalik ibnAnas Beirut: D ałal-Fikr, 1989.

Al-Mahmashani, Subhi Rajib. Turath al-Khulafa' al-Rashidin fi al-Fikih wa al-Qadha'. Beirut: D as al-'Tlm li al-Mulayin, 1984.

Muhammad, Muhammad Abdur Rahim. al-Madkhal ila Fikihal-ImamAli r.a K airo: D as alHAdith, 1988.

Al-Nadwi, Ali Ahmad. al-Qawa'idal-Fikihiyjah Damaskus: D ał -al-Q alam, 1986.

Salam, Abu Ubaid al-Q asim ibn. Kitabal-Amval. Beirut: D as al-Kutub al-'Ilmiyyah, 1986.

Al-Thaba'i, Muhammad Husein al-Thaba. al-Mizanfi Tafsiral-Qur'an Beirut: Muassasah alA'lamiłi al-Mathu at, 1991.

Al-Thusi, A bu Ja'far Muhammad ibn Husain ibn Ali. al-Mabsutei Fiqhal-Imamiyah t.tmp: alMaktbah al-Murtadhiyyah, t.th.

Al-Zarqa, A hmad ibn Syaikh Muhammad. Sharhyal-Qawäidal-Fiqhiygah D amaskus: D aæalQ alam, 1996.

Al-Zuhaili, Wahbah. al-Tafsival-Munizfí Aqidah wa al-Shari'gh wa al-Minhaj. Beirut: D ał alFikr, 1991. 